\title{
An analysis of patient information leaflets supplied with medicines sold by pharmacists in the United Kingdom
}

\section{Cheryl Twomey}

\section{The author}

Following a research career in microbiology, Cheryl Twomey qualified as a librarian in 1999.

She is currently Electronic Projects Librarian at the London Library and Information

Development Unit that provides leadership, expertise and support to London Region NHS

library and information staff. Previously she was Assistant Librarian at the Homerton Hospital NHS Trust.

Email: ctwomey@llidu.ac.uk

\section{The Occasion}

The basis for this article is a dissertation completed for the MA in Information Services Management at the University of North London. The author was awarded the 2000 LIRG Postgraduate Student Prize for this work.

\begin{abstract}
The primary aim of this exploratory study was to analyse the design factors contributing to the reading ease and comprehension of medicinal information leaflets. Good practice guidelines on general typography and layout were chosen from the literature and compared with European Commission guidelines on preparing package leaflets. The suitability of the guidelines for evaluating package inserts was investigated using leaflets accompanying thirteen different medicines available from pharmacies. With minor revision, the design recommendations were appropriate for developing over the counter medicinal leaflets. There was general agreement that simplicity is the key to good information design. It was concluded that the design of readable medicinal package inserts is a complex, process. Consumer participation is essential and advice from a professional designer highly desirable.
\end{abstract}

\section{Acknowledgements}

The author is grateful to Sheila Patel for supply of the patient information leaflets and to Eileen Milner and Rosemary McGuinness of the University of North London.

\section{Introduction}

Patients are being encouraged by recent government initiatives to take greater personal responsibility, in partnership with appropriate professionals, for health care decisions (Department of Health, 1997a; 2000). Consumer choice has increased in the last decade with legislative action allowing a wider range of more potent medicines previously only available on prescription being reclassified for sale in pharmacies (Blenkinsopp \& Bradley, 1996). Access to high quality information is essential if these drugs are to be used safely and effectively without clinical supervision.

Since 1998 all UK medicinal products, whether dispensed by a pharmacist or bought over the counter, have to be supplied with an authorised patient information leaflet (European Commission, 1992; Medicines Control Agency, 1998a). Manufacturers need to compile leaflets that comply with this legislation, fit into the drug packaging and are understood by a general population with diverse abilities and needs (Griffin \& Griffin, 1996). The few studies that have evaluated the quality of medicinal package inserts (Bradley, 1994; Wong, 1999) have used readability formulae as assessment tools but these are limited in their scope for improving 
the quality and value of information leaflets (Redish, 1981). Information design not only improves the presentation of a document, it is also instrumental in attracting, motivating and promoting the understanding of the reader (Orna \& Stevens, 1991).

In this exploratory study good practice design guidelines have been compiled from the literature and used to assess a sample of patient information leaflets (PIL) supplied with over the counter (OTC) medicines in the United Kingdom. As far as is known this is the first study to investigate the design of OTC medicinal package inserts.

\section{Methodology}

Guidelines on information design from the literature were pooled and areas of consensus and dissimilarity identified. A set of evaluated guidelines was compiled and compared to:

- the guideline on the readability of the package leaflet produced by the European Commission (1998)

- a sample of current OTC medicinal information leaflets.

Literature searches Between October 1998 and February 1999, searches were made using MEDLINE, PsycLIT, LISA Plus, Science Citation Index of BIDS and the Internet. Free text and subject heading searches were conducted covering: medicines, patient information leaflets, health education, information and product design, communication, guidelines, evaluation studies, patient satisfaction and quality indicators. Investigation of hyperlinks and the reference sections of articles from initial results gave additional sources. Guidelines based on research evidence, the psychology of reading and the practice of graphic designers were selected. Wherever possible the original source of the guidelines was traced so that agreement amongst authors was not spurious.

Patient information leaflets Leaflets accompanying products whose legal status had changed from prescription only to pharmacy sale since 1993 were chosen for analysis. The starting date was selected as the time when the Medicines Control Agency (MCA) introduced a new structured annual timetable to expedite the reclassification of prescription only medicines (Department of Health, 1994). The products containing single active substances were identified from the Chief Medical Officer's Annual Reports (Department of Health, 1994; $1995 ; 1996 ; 1997 b ; 1998)$ supported by information from the MCA $(1997,1998 b)$ and its advisers (Lawson, 1996). Package inserts were obtained from a retail pharmacist, photocopied and details, such as size and colour that did not show on the photocopies, recorded.

Leaflet characteristics The leaflets were assessed as follows: 1) linear measurements were made by eye to the nearest $0.5 \mathrm{~mm}$ using a millimetre rule; 2 ) transparency was registered when print from the reverse side showed through the leaflet; 3) type size was estimated from the text occupying the majority of the leaflet. Measurement was made in millimetres, from the top of an ascender of a letter to the bottom of a descender in one line, and converted to 'points' $(1 \mathrm{~mm}$ is approximately equivalent to 3 points); and 4) typefaces were identified by comparison to typographic encyclopaedias (Jaspert, 1970; V \& M Typographic, 1974).

\section{Information Design Guidelines}

Good design practice identified from the literature originated from a range of organisations and researchers with differing backgrounds and interests: Association of the British Pharmaceutical Association (1990); Basic Skills Agency (1999); Hartley (1994, 1998, 1999); National Information Forum (1996); Orna and Stevens (1995); Plain English Campaign (1998); Raynor (1992); Royal National Institute for the Blind (1997); and Stone (1992). The benchmark 
criteria shown in Table 1 were formulated with the general reader in mind, as OTC medicines are available to all members of the public. In particular, the advice of the Basic Skills Agency (1999) and the Royal National Institute for the Blind (1997) was heeded to include visually impaired and older people and those with reading difficulties. Simplicity, clarity and the importance of planned spacing are emphasised in the literature. The choice and orientation of page size and the inclusion of illustrations will determine many of the subsequent design decisions (Hartley, 1999). However, once the format, spacing (between headings, paragraphs and lines) and typographic or colour cues have been chosen they must be used consistently throughout the leaflet (Hartley, 1994; Orna \& Stevens, 1995). Significant differences between authors were only revealed in two areas: type size and justification of text. 


\section{Paper \\ A5 size is preferable A leaflet is more likely to be kept if it is a convenient size e.g. able to fit in a medicine bag or pocket \\ Non-transparent paper Text showing through from the reverse side makes letters and words difficult to distinguish \\ Matt surface Glossy paper makes reading difficult by reflecting too much light}

\section{Layout}

Consistent use of layout Consistent organisation within the leaflet gives visual clues to the proximity and grouping of textual elements and headings

Plenty of white space A page of close-set type easily daunts readers and there is a long tradition in design that the 4 margins are never equal in width

Clear separation of columns When space is limited clearly separating columns of text, including using vertical rules, can help reading

\section{Typography}

12-point minimum type size Twelve-point text produces documents intended for general readers

Conventional typefaces The general public is familiar with such typefaces, that are clear and legible when printed and copied

Not more than 2 typefaces One face for the text and one for the captions is less confusing for the reader

Interline spacing of $125 \%$ of 12 -point type $(5 \mathrm{~mm}$ Strips of white space between lines help the eye to separate one line from another; $125 \%$ of the type size as the line space avoids the text looking cramped and crowded but any wider than this makes the lines appear to float apart

Avoid unnecessary capitals Lower case letters give shape to words and so are easier to recognise and read than all upper case
Jnjustified right-hand margins An overall even exture helps reading by allowing the eye to link words together and is best achieved using injustified text

Maximum line length of 50-65 characters or 8-11 words Very short lines break up sentences too much; long lines tend to lose attention

Text should not be wrapped around illustrations This can result in unaligned left-hand margins and fery short line lengths

Text should not be printed over pictures Over printing of pictures, especially if a dark background s used, makes reading very difficult as it limits fontrast and confuses the eye

\section{Headings}

Fonsistent use of headings This aids readability and location of information by clearly differentiating petween groups of related items

rable of contents desirable This helps to locate ppecific instructions or explanations and can be a fery important aid in a long leaflet

Numbered headings recommended These help ross-referencing and avoid repetition

Bullet points recommended This format is clearer or sequential information

Bold or boxed in type for emphasis This is preferable to all upper case and multiple cueing pystems can be confusing

\section{Colour}

Black print on a white background This gives the pest contrast and greatly enhances readability especially for people with visual impairment

Pne extra colour, if used, for headings This can pe helpful, if used consistently and the contrast with he background maintained, to emphasise headings

Yellow should not be used The appearance of yellow printing ink is as good as invisible to visually mpaired people 
Type size Ensuring the suitability of type for a particular audience has long been a main principle of typography (Orna \& Stevens, 1995). The Royal National Institute for the Blind (1997) uses 12-point text to produce documents intended for general readers and believes others should aspire to this level of print size, in agreement with the National Information Forum (1996). Independent studies reviewed by Hartley (1999) have shown that a type size of 12- or 14-point is helpful to older readers. A minimum of 14-point is advised for materials aimed at partially sighted and blind people, a significant proportion of whom can read large print (Royal National Institute for the Blind, 1997) but use of this size could make the PIL appear too long for the 'average' reader. Additionally, according to the Basic Skills Agency (1999) too large a print can deter adults with reading difficulties as the material may look as though it is intended for children. Therefore, 12-point type size has been adopted as a benchmark in this study.

Justification Justified text (straight edged left and right margins) causes 'rivers' of white space to appear as the gaps between words are adjusted to fill the line length so the eye has difficulty linking words together and slows down reading (Orna \& Stevens, 1995). Thus, the Royal National Institute for the Blind (1997) prefers unjustified text (jagged right-hand margin). Although Hartley (1999) asserts that research suggests there is little to choose between the two and is largely a matter of style, he does concede that unjustified text is probably more flexible for information leaflets. Therefore unjustified right-hand margins has been used as the standard in this study.

\section{Official guidelines}

Advice given by the regulators on page size, paper type, headings and emphasis (EC, 1998) does not differ significantly from the literature guidelines with two main exceptions. The EC (1998) recommends the rather low minimum of 8-point type and this affects their advice on inter-line spacing (at least $3 \mathrm{~mm}$ ). It is also suggested that sentences with more than 20 words should be avoided and lines with more than 70 characters not used but the basis for these statements is not referenced. However, authoritative sources (Orna \& Stevens, 1995; Plain English Campaign, 1998; Royal National Institute for the Blind, 1997) recommend more moderate line lengths for ease of reading, even in continuous text, leading to the guidance in Table 1. The authorities (EC, 1998) give no or very general advice on margins, white space, column widths, paragraph spacing, typefaces and justification. The official directions regarding illustrations are limited. They are allowed only in addition to text if they help understanding and they must not be promotional.

\section{Package insert case studies}

Nineteen prescription medicines containing different active ingredients were identified as having changed legal status to pharmacy sale between 1993 and 1998. Photocopies of package inserts were obtained for thirteen medicines whose details are shown in Table 2. The other PILs were not available because the pharmacist who provided the leaflets did not stock two of the products, did not know the legal status had changed in one case and could not open three packs as they had security seals. 
Table 2: Characteristics of over the counter medicinal package information leaflets

\begin{tabular}{|c|c|c|c|c|}
\hline Trade name & Active ingredient & $\begin{array}{l}\text { TREATMENT } \\
\text { USES }\end{array}$ & $\begin{array}{l}\text { Legal status } \\
\text { change date }^{*}\end{array}$ & $\begin{array}{l}\text { Leaflet } \\
\text { date }\end{array}$ \\
\hline $\begin{array}{l}\text { Adcortyl in } \\
\text { Orabase paste }\end{array}$ & $\begin{array}{l}\text { triamcinolone } \\
\text { acetonide }\end{array}$ & mouth ulcers & 1994 & Nov 1994 \\
\hline Corlan pellets & $\begin{array}{l}\text { hydrocortisone } \\
\text { sodium succinate }\end{array}$ & mouth ulcers & 1994 & Jan 1994 \\
\hline $\begin{array}{l}\text { Diflucan One } \\
\text { capsule }\end{array}$ & fluconazole & vaginal thrush & 1995 & Jun 1997 \\
\hline Feldene P gel & piroxicam & pain relief & 1994 & Oct 1996 \\
\hline $\begin{array}{l}\text { Motilium } 10 \\
\text { tablets }\end{array}$ & $\begin{array}{l}\text { domperidone } \\
\text { maleate }\end{array}$ & $\begin{array}{l}\text { stomach queasiness, } \\
\text { bloating, heartburn }\end{array}$ & 1998 & Jun 1998 \\
\hline Nizoral shampoo & ketoconazole & dandruff & 1995 & Jul 1997 \\
\hline $\begin{array}{l}\text { Pepcid AC Acid } \\
\text { Control tablets }\end{array}$ & famotidine & $\begin{array}{l}\text { heartburn, dyspepsia, } \\
\text { excess acid }\end{array}$ & 1993 & Jan 1996 \\
\hline $\begin{array}{l}\text { Rhinolast nasal } \\
\text { spray }\end{array}$ & $\begin{array}{l}\text { azelastine } \\
\text { hydrochloride }\end{array}$ & hayfever & 1996 & Nov 1996 \\
\hline Solpaflex gel & ketoprofen & $\begin{array}{l}\text { reduction of pain and } \\
\text { swelling }\end{array}$ & 1993 & Apr 1996 \\
\hline $\begin{array}{l}\text { Syntaris nasal } \\
\text { spray }\end{array}$ & flunisolide & hayfever & 1995 & Dec 1995 \\
\hline $\begin{array}{l}\text { Tagamet } 100 \\
\text { tablets }\end{array}$ & cimetidine & $\begin{array}{l}\text { heartburn, dyspepsia, } \\
\text { excess acid }\end{array}$ & 1993 & Aug 1995 \\
\hline Traxam gel & felbinac & $\begin{array}{l}\text { reduction of pain and } \\
\text { swelling }\end{array}$ & 1994 & Aug 1995 \\
\hline Zovirax cream & aciclovir & cold sores & 1993 & Sept 1996 \\
\hline
\end{tabular}

*Denotes year when the legal change to pharmacy sale was made; the product was not necessarily marketed in the same year

-This is the date of the leaflet included in the package at the time of the study (1999) 
Page and paper characteristics All the leaflets were printed on single sheets but had a wide range of dimensions. Most (9/13) were close in area to A5 whilst the remainder were smaller. There was some correlation between the area of the leaflet and the pharmaceutical form and quantity of the product. For example, one of the smallest products, Adcortyl $5 \mathrm{~g}$ paste, contained a leaflet half the area of the insert supplied with one of the largest products, Nizoral $60 \mathrm{ml}$ shampoo. However, very similar products, e.g. Feldene and Solpaflex, had very different size leaflets indicating other factors were influencing the dimensions of the insert. Four leaflets were transparent but the measure used in this study was rather insensitive so this figure may increase when the original leaflets are viewed. All the PILs had a matt surface.

Layout Formats were used consistently except where illustrations were included. To maximise the use of space, the format had to vary in the Rhinolast, Syntaris, Traxam and Zovirax leaflets to accommodate text that related directly to the diagrams. Two thirds (10/13) of the leaflets had a portrait style orientation and most (6/10) of these used a single-column text only format, as Hartley (1999) found with prescription PILs. In other leaflets with diagrams, one used landscape and two used portrait. The sample is too small to confirm the conclusion of Hartley (1999) that landscape orientation is more likely to be used when there is a need for illustrations and two-column text.

Separation between columns was judged to be adequate ranging from 4 to $6 \mathrm{~mm}$. This is equivalent to 2-3 times the total type size although this was small (point 6-7) in this group of PILs. Vertical lines were not used to separate columns in any of the relevant leaflets. Margins could not be measured as these did not show clearly enough on the photocopied leaflets. Additionally, whether the amount of white space was adequate is probably a matter of opinion, best resolved by evaluation of the original PILs with consumers and graphic designers.

Type size No leaflets had type as large as 12-point although two (Nizoral and Feldene) had 11-point type. Four had 8 to 10-point and seven had 6 to 7-point type. Thus, half of the leaflets used a print size lower even than the EC guidelines (1998). However, all the leaflets were prepared before these guidelines became effective in January 1999. Two leaflets with 6point type were about half A5 size and accompanied small volume products (Adcortyl and Corlan) used for mouth ulcers. Increasing the area of these PILs to allow larger type may be difficult due to the small size of their packaging. The remaining PILs that had very small type contained illustrations.

Typeface None of the PILs had bizarre, unusual or indistinct typefaces. Nearly all the leaflets (12/13) use normal type for most of the text and the bold version for the headings. Nonetheless, this applies to typeface only and does not reflect the less simple use of colour, capitals and boxing used in some PILs.

Inter-line spacing None had an inter-line space of $5 \mathrm{~mm}$ or more but the spaces used were all related to the print size and consistent with the $125 \%$ rule of thumb. All the PILs had unjustified right-hand margins. This is probably the best solution for these leaflets, as they do not contain much prose text and the sense often demands short lines.

Line lengths The line lengths for each sample leaflet varied considerably so the length of the longest line in each leaflet was taken as a very rough measure. Most (9/13) PILs that had single columns of text had much longer lines (range 13-20 words; 68-132 characters) than the recommendation for prose text (8-11 words; 50-65 characters). Two single column PILs 
came within the advised range but one was a long narrow leaflet (Diflucan) and the other (Feldene) had one of the largest type sizes (11-point). The remaining leaflets falling within the recommended range had two columns of text (Pepcid and Traxam).

Headings As for prescription drug leaflets (Patient i, 1997), the majority of the leaflets $(10 / 13)$ used left-ranging headings with the remainder having centred ones. Most inserts had two or less headings and used typographic and colour cues consistently. However, this is not as simple as it sounds. Seven PILs had obvious headings that were clearly distinguishable from the text. Others had consistent use of headings but multiple cueing systems, using a combination of bold and italic print with variations of colours, capitals and boxing, which appeared confusing. In others, similar devices were used for emphasis of important information and it was difficult to differentiate these from the headings. There was no obvious connection between the use of 'complex' headings and the treatment uses of the medicines. These PILs were prepared only slightly earlier (median 1995) than those with 'simple' headings (median 1996).

The newest leaflet, Motilium prepared in June 1998, was the only one to have numbered headings whilst none had a table of contents. This is not surprising since this advice from the European Commission (1998) post-dates all of the PILs. Bullet point summaries were present at some point in nearly all of the leaflets (10/13) although they were only used extensively in two (Motilium and Syntaris). Eight PILs had bullet points for the 'precautions' section only.

Emphasis Capitals were used in almost half the leaflets for headings (6/13) and three had complete sentences in capitals to indicate warnings. As research suggests lower case letters are easier to read (Hartley, 1994), manufacturers would be wise to avoid unnecessary capitals for important information and for long headings (European Commission, 1998). All the leaflets had bold headings.

The text of two PILs (Feldene and Nizoral) did not contain any emphasised areas. In the remainder attention was drawn to the content in the following ways (number of leaflets in brackets): bold type (11), capitals (7), boxing (5), colour (4), underlining (2) and italic type (1). However, only three PILs had simple devices. Some had quite complex arrangements; for example, boxing, colour, bold type and capitals highlighted single warnings in the Rhinolast and Syntaris leaflets. The product name was printed in capitals or bold type in five leaflets. This may not accord with minimisation of the brand name as indicated by the EC (1998).

Colour All the leaflets except one had a white background. Most (8/13) had black print on white paper whilst four had royal blue print. The Diflucan leaflet had a two-tone blue background and purple print, probably the worst combination for making reading difficult (Basic Skills Agency, 1999). Only the Rhinolast and Zovirax leaflets had another colour typeface and this was reserved for the headings. However, since the headings were also printed in bold type or boxed, an extra colour, of whatever hue, is possibly unnecessary. Yellow ink was used in the headings and illustrations in two leaflets (Traxam and Syntaris) counter to the advice of the Royal National Institute for the Blind (1997).

Illustrations None of the PILs were printed over pictures or had text wrapped around the illustrations. Six PILs had illustrations: three using diagrams, two using pictograms and one using both. 


\section{Using the guidelines}

The guidelines were developed with the aim of helping to produce planned, simple and clear documents focused on the needs of users. Using the study PILs allowed these guidelines to be revised to accommodate the particular circumstances of package inserts:

- the advice given for maximum line length was difficult to apply since the length of lines in the leaflets varied considerably

- consistency in the use of headings alone did not always help the appearance of a document. Therefore, this advice should be extended to include headings clearly differentiated from the text in accordance with simplicity (Hartley, 1999).

The designs ranged from 'simple' ones that mainly followed the guidelines to much more complex arrangements. For example, the PIL for Feldene (pain relief gel) had 11-point type and simple bold headings clearly differentiated from the text. Black instead of blue print and bullet points may improve its readability. The insert for Syntaris (for hayfever) was much more complex with 7-point type, more than two typefaces, sentences in italic and wide use of capitals, bold type, boxing and colour. Although this leaflet contains possibly useful diagrams on how to use the nasal spray it could still be simplified by following the guidelines.

This investigation was essentially exploratory and did not expect to reach overall conclusions on the design success, or otherwise, of OTC medicinal leaflets. However, small changes in some PILs could be tested with consumers immediately. Reducing the very large symbol that dominates the first page would considerably shorten the Tagamet leaflet. Yellow ink used in the headings and illustrations in the Traxam and Syntaris inserts could be replaced with a darker colour to increase readability. None of the leaflets examined displayed the Crystal Mark awarded by the Plain English Campaign (1998) as a guarantee of a document's clarity of design as well as clearly and plainly written text. It is unknown whether the pharmaceutical companies involved had applied for the award.

\section{Discussion}

There was general agreement amongst those committed to communicating information to members of the public of the fundamentals of good design. Although Orna and Stevens $(1991,1995)$ state that the principles of typographic design are based on well-founded research, the evidence base for the guidelines reported here requires systematic review. However, this should be undertaken within the context of document design being mainly a problem-solving task operating within the constraints of content, space, time and budget. The skill and flair of a professional designer may be required whilst organisations such as the Plain English Campaign (1998) offer guidance on communicating clearly and effectively. However, the final decisions should be based on consumer evaluation.

The benchmarks were chosen so that the design of the leaflet made it accessible to as many people as possible including older people and those with literacy problems. They will not cater for non-English speakers, many blind consumers and people with learning difficulties. It would be impractical to expect manufacturers to supply leaflets for all these groups in the packaging but some mechanism allowing access to drug information for these members of society needs investigation.

This study raised the difficulty of obtaining leaflets accompanying OTC medicines, whether the originals or copies, without expense or personal contacts. A widely available compendium of OTC package inserts as exists for prescribed medicines (Walker, 1999) would benefit consumers as well as health professionals. PILs could not be obtained for six products 
but the sample assessed represented the main reasons consumers use an OTC medicine (Blenkinsopp \& Bradley, 1996) and a range of manufacturers.

Although the sample of PILs produced by OTC manufacturers was very varied, the pooled published guidelines were generally suitable for assessing the design of drug package inserts. However, the recommendation of a maximum line length of 50-65 characters was not easily applied to this type of leaflet. Some guidance on line length is needed but it is dependent on the initial choice of layout, such as single or double columns of text. Newton et al. (1998) found that single column text was preferred to newspaper-style columns in a leaflet on gout but further investigation is required with package inserts. Examination of the sample leaflets also showed that headings need to be used not only consistently but also clearly separated from the text if they are to act as good navigational aids.

The advice to use 'plenty of white space' was kept in the guidelines although it is difficult to assess and is probably best determined by consulting consumers and designers. A better indicator for the measure of transparency than the one used in this study would be the weight of the paper $\left(\mathrm{g} / \mathrm{m}^{2}\right)$, given the availability of appropriate weighing equipment. The EC (1998) recommends a minimum weight of $40 \mathrm{~g} / \mathrm{m}^{2}$ statement but the opacity of this weight requires confirmation. However, thicker paper may make the PILs more difficult to fold and fit into the packs.

Overall, this study confirmed previous advice (Basic Skills Agency, 1999; Hartley, 1994; Orna \& Stevens, 1995; Royal National Institute for the Blind, 1997) that the initial choice of page size and the decision to include diagrams is important since it affects many subsequent design characteristics, especially type size. About half the inserts did not follow the recommendations for simplicity and clarity. Considerable variation in size, shape, typography and layout was evident in the sample OTC leaflets, confirming previous findings with prescription medicine leaflets (Hartley, 1999). None of the sample had a type size as large as that recommended by the Royal National Institute for the Blind (1997) for adult readers. However, increasing type size, and associated inter-line spacing, would make the PIL longer. Type size, the usefulness of illustrations and the devices used to emphasise headings and warnings require further investigation with consumers to establish best practice. The EC (1998) has indicated that it is open to making changes in the legislation if they are shown to improve readability.

\section{Conclusions}

Production of patient package inserts is a complex, process requiring regulatory approval. As this is the first study to investigate the design of OTC medicinal package inserts more questions than answers were raised. The following areas would benefit from more detailed research:

- the evidence underpinning the guidelines compiled in this study

- evaluation by consumers of the readability of PILs revised using the good design guidelines

- user preference regarding the style of layout and typography, especially type size, and the use of illustrations in medicinal package inserts and the consequent effects on comprehension

- the effect of consumer involvement on the design of medicinal PILs

- the value for pharmaceutical companies of consulting a professional information designer and the Plain English Campaign when drafting package inserts 
Following establishment of the most effective layout and typography, approaches should be made to the European Commission and Medicines Control Agency to supplement or change the guidance given to manufacturers for the preparation of patient information leaflets. Good information design is important but attention to this alone does not produce high quality patient information leaflets. Well written text, evidence-based information and consumer testing are also essential.

\section{References}

Association of the British Pharmaceutical Industry (1990) 'Patient information: advice on the drafting of leaflets' in FO Wells (ed.) Medicines good practice guidelines, Belfast: Queen's University

Basic Skills Agency (1999) Making reading easier, London: Basic Skills Agency (reprinted in 1999, BSA uncertain of original publication date)

Blenkinsopp A \& Bradley C (1996) 'Patients, society, and the increase in self medication', British Medical Journal, 312 (March 9), 629-32

Bradley B, Singleton M \& Li Wan Po A (1994) 'Readability of patient information leaflets on over-the-counter (OTC) medicines, Journal of Clinical Pharmacy and Therapeutics, 19, 7-15

Department of Health (1994) On the state of the public health. The annual report of the Chief Medical Officer of the Department of Health for the year 1993, London: HMSO

Department of Health (1995) On the state of the public health. The annual report of the Chief Medical Officer of the Department of Health for the year 1994, London: HMSO.

Department of Health (1996) On the state of the public health. The annual report of the Chief Medical Officer of the Department of Health for the year 1995, London: HMSO.

Department of Health (1997a) The new NHS, Cm 3807, London: The Stationery Office

Department of Health (1997b) On the state of the public health. The annual report of the Chief Medical Officer of the Department of Health for the year 1996, London: HMSO

Department of Health (1998) On the state of the public health. The annual report of the Chief Medical Officer of the Department of Health for the year 1997, London: Stationery Office

Department of Health (2000) The NHS Plan: a plan for investment, a plan for reform, Cm4818-I, London: Stationery Office

European Commission (1992) 'Council Directive 92/27/EEC of 31 March 1992 on the labelling of medicinal products for human use and on package leaflets', Official Journal of the European Communities, No. L, April 30, 113/8-12

European Commission (1998) A guideline on the readability of the label and 
package leaflet of medicinal products for human use (September 1998), Brussels: Pharmaceutical Committee, European Commission

Griffin JP \& Griffin JR (1996) 'Informing the patient', Journal of the Royal College of Physicians of London, 30 (2), 107-11

Hartley J (1994) Designing instructional text, London: Kogan Page (3rd ed.)

Hartley (1998) 'Return to sender. Why written communications fail', Psychologist, October, $477-80$

Hartley J (1999) ' What does it say? Text design, medical information and older readers', in DC Park, RW Morrell \& K Shifrin (eds.) Processing of medical information in aging patients. Cognitive and human factors and perspectives, Mahwah, NJ: Erlbaum

Jaspert WP; Berry WT \& Johnson AF (1970) Encyclopaedia of typefaces, London: Blandford Press (4th ed.)

Lawson D (1996) 'Stringent safeguards for medicines classification', in OTC Directory: treatments for common ailments 96/97, ii-iv

Medicines Control Agency (1997) Proposals to amend the prescription only medicines order (MLX 243, 23 December 1997), London: Medicines Control Agency

Medicines Control Agency (1998a) 'Labelling and leaflet Directive 92/27/EEC: have you met the requirements?', MAIL, No. 105, January/February, 4

Medicines Control Agency (1998b) Proposed amendments to the Prescription Only Medicines (human use) Order 1997 (MLX 244, 3 June 1998), London: Medicines Control Agency

National Information Forum (1996) How to provide information well, London: National Information Forum

Newton L; Newton D; Clark J; Kenny T; Moseley D; Purves I \& Wilson R (1998) 'Patient information leaflets: producing understandable PILs', Journal of Information Science, 24 (3), $167-81$

Orna E \& Stevens G (1991) 'Information design and information science: a new alliance?', Journal of Information Science, 17, 197-208

Orna E \& Stevens G (1995) Managing information for research, Buckingham: Open University Press.

Patient i (1997) 'Simple is best, professor tells leaflet designers', Patient $i$, Issue 6, September, 10-1

Plain English Campaign. (1998). Plain English from the Plain English Campaign [Online]. Available: http://www.plainenglishcampaign.com/ [1999, March 17] 
Raynor DK (1992) 'Writing patient information - a pharmacist's guide', Pharmaceutical Journal, August 8, 180-2

Redish JC (1981) 'Understanding the limitations of readability formulas', IEEE Transactions on Professional Communication, PC-24 (1 March), 46-8

Royal National Institute for the Blind (1997), Clear print guidelines, London: RNIB

Stone L (1992) 'Information to patients about medicines', in FO Wells (ed.) Medicines: responsible prescribing, Belfast: Queen's University.

V \& M Typographic (1974) The type specimen book, Brooklyn, NY: V \& M Typographic Inc.

Walker G (1999) ABPI Compendium of data sheets and summary of product characteristics 1999-2000, London: Datapharm.

Wong ICK (1999) 'Readability of patient information leaflets on antiepileptic drugs in the UK', Seizure, 8, 35-7. 